\title{
Effects of Intrauterine Food Restriction and Long-Term Dietary Supplementation with L-Arginine on Age-Related Changes in Renal Function and Structure of Rats
}

\author{
FRIDA ZALADEK GIL, SANDRA REGINA R. LUCAS, GUIOMAR NASCIMENTO GOMES, \\ MARIA DE FÁTIMA CAVANAL, AND TEREZILA MACHADO COIMBRA \\ Department of Physiology, Renal Physiology, and Metabolic Biology [F.Z.G., G.N.G., M.d.F.C.], \\ Morphology Department, Embryology Division [S.R.R.L.], UNIFESP-EPM, São Paulo, Brazil, 04023-900, \\ Department of Physiology and Biophysics [T.M.C.], University of São Paulo Ribeirão Preto School of \\ Medicine, São Paulo, Brazil, 01246-903
}

\begin{abstract}
We have previously demonstrated that restricting intrauterine food by 50\% in 3-mo-old rats produced lower nephron numbers and early-onset hypertension, the latter being normalized by L-arginine administration. In 18-mo-old rats, such restriction increased glomerulosclerosis. In this study, we expanded our investigation, evaluating functional, morphologic, and immunohistochemical parameters in intrauterine-food-restricted 18-mo-old rats, either receiving Larginine (RA18) or not (R18). Age-matched, non-food-restricted controls were assigned to similar groups with L-arginine (CA18) and without (C18). After weaning, L-arginine was given daily for $17 \mathrm{mo}$. No functional or morphologic changes were observed in $\mathrm{C} 18$ rats. The R18 rats developed early-onset hypertension, which persisted throughout the observation period, as well as significant proteinuria from 12 mo on. In RA18 rats, L-arginine decreased both blood pressure levels and proteinuria, and glomerular diameter was significantly smaller than in $\mathrm{R} 18$ rats $(115.63 \pm 2.2$ versus $134.8 \pm 1.0$ $\mu \mathrm{m}, p<0.05)$. However, in RA18 rats, glomerular filtration rate
\end{abstract}

ABSTRACT

remained depressed. Although L-arginine prevented glomerulosclerosis $(\mathrm{R} 18=14 \%, \mathrm{RA} 18=4 \% ; p<0.05)$, glomerular expression of fibronectin and desmin was still greater in RA18 rats than in controls. Our data show that, although L-arginine prevented hypertension and proteinuria, glomerular injury still occurred, suggesting that intrauterine food restriction may be one of the leading causes of impaired renal function in adult life. (Pediatr Res 57: 724-731, 2005)

\section{Abbreviations}

GFR, glomerular filtration rate

L-Arg, L-arginine

NOS, nitric oxide synthase

PAH, para-aminohippurate

RPF, renal plasma flow

SHR, spontaneously hypertensive rat
Maternal undernutrition during gestation may affect various physiologic functions in the newborn infant. Human studies have shown correlations between intrauterine growth restriction and susceptibility to a number of chronic diseases in adulthood, including coronary heart disease, stroke, and hypertension (1-4). Several studies have demonstrated that intrauterine food restriction derives from alterations in quality or quantity of diet, resulting in hypertension and a significant reduction in nephron number in the offspring

Received April 8, 2004; accepted September 27, 2004.

Correspondence: Frida Zaladek Gil, M.D., Ph.D., Department of Physiology, Federal University of São Paulo, UNIFESP-EPM Rua Botucatu, 862, 5 CEP: 04023-900 São Paulo SP, Brazil; e-mail: frida@ecb.epm.br

Supported by grants from the Fundação de Amparo à Pesquisa do Estado de São Paulo (FAPESP).

DOI: 10.1203/01.PDR.0000159514.06939.7E
(5-8). According to the "fetal programming" hypothesis, these disorders may be caused by in utero fetal adaptations to maternal undernutrition, which permanently changes postnatal metabolism and growth characteristics $(9-11)$. On the other hand, aging is associated with loss of renal mass, which, by itself, has little impact on overall renal function but may increase the vulnerability of the kidney to other injuries (12, 13). Functional changes include increased renal vascular resistance, a lower GFR, and a higher filtration fraction. In humans, structural changes include progressive renal sclerosis, combined with glomerulosclerosis and interstitial fibrosis (13). In aging rats, proteinuria is often observed concomitantly with focal and segmental glomerular sclerosis (14), features not found in human renal senescence (13). Although differences among species have been reported with regard to the aging process, in vivo accumulation of oxidative end products and 
advanced glycation end products is common in the tissues of mammalian species (13).

In a previous study involving 3-mo-old rats, we demonstrated that intrauterine food restriction causes significant renal function impairment and also provokes hypertrophy in the remaining glomeruli and decreases absolute nephron numbers $(5,6)$. In subsequent studies, we showed that intrauterine food restriction could also be a determinant of early-onset proteinuria and glomerulosclerosis in aged rats (15). Oral administration of L-Arg, given to intrauterine-food-restricted rats at 8 or $12 \mathrm{wk}$ after weaning, prevented hypertension, although renal function parameters remained low (16). Oral administration of L-Arg, the natural precursor of nitric oxide (NO), has been shown to protect against renal injury in several experimental models, including a model of age-related reduction in renal function and a model of hypercholesterolemia (17-20). In the present study involving 18-mo-old rats from dams subjected to $50 \%$ food restriction throughout pregnancy, we extended our investigation, supplementing postweaning diets with oral L-Arg and performing functional, morphologic, and immunohistochemical evaluations. Because hypertension alone plays an important role in the development of renal disease (21-24), reduced availability of NO could be involved both in the endothelial dysfunction observed in some models of hypertension and in the progression of glomerulosclerosis. This study aimed to investigate the extent of vascular involvement in the development of kidney disease in this experimental model. Our data demonstrate that, although L-Arg prevents hypertension and proteinuria, glomerular injury and reduction in renal function still occur, indicating that intrauterine food restriction can be a significant cause of impaired renal function and nephrosclerosis later in life.

\section{MATERIALS AND METHODS}

Experimental model. Male Wistar rats, obtained from Escola Paulista de Medicina (EPM) were studied. The groups comprised the offspring of dams who were given food ad libitum and those of dams who were subjected to $(50 \%)$ food restriction throughout pregnancy. The groups of dams and offspring were designated group C (control) and group R (restricted). The 50\% dietary restriction of the dams was determined on a daily basis, according to the amount eaten by the control group. All dams were housed and fed individually. After giving birth, all dams were given free access to food and water, and each litter, consisting of six male rats, was allowed to remain with the dam for $28 \mathrm{~d}$. To maintain litters of six, females were included when there was an insufficient number of males, although the females were excluded at weaning. After weaning, the rats were placed in individual cages, with free access to food and water, until they reached $18 \mathrm{mo}$ of age. All experimental procedures were conducted in accordance with our institutional guidelines for animal handling.

The rats were divided into four subgroups: group C18 (controls), group R18 (intrauterine-food-restricted), group CA18 (controls receiving 2\% L-Arg solution dissolved in $2 \%$ sucrose in drinking water), and group RA18 (intrauterinefood-restricted and receiving L-Arg solution dissolved in sucrose in drinking water). Rats in the C18 and R18 groups received a $2 \%$ sucrose-only solution. The L-Arg dose was similar to that used by Reckelhoff et al. (19), and the sucrose solution was used as a vehicle to improve L-Arg ingestion. Supplementation with the L-Arg solution or the sucrose-only solution began immediately after weaning and was continued until the rats reached the age of $18 \mathrm{mo}$ (study duration, $17 \mathrm{mo}$ ). Sucrose solution intake was measured daily to minimize differences between groups regarding L-Arg intake. Study rats received $\sim 1.2 \mathrm{~g} \mathrm{~L}-\mathrm{Arg} / \mathrm{kg}$ body weight $/ \mathrm{d}$. Arterial pressure was evaluated monthly, from 2 mo of age, by tail plethysmography.

Renal function studies. The animals were anesthetized with sodium thiopental $(30 \mathrm{mg} / \mathrm{kg})$ and placed on a heated table to maintain body temperature at $37^{\circ} \mathrm{C}$. After tracheotomy, polyethylene catheters were placed in the jugular vein (for infusions) and the carotid artery (for blood sampling). Urine was collected from a catheter inserted into the bladder. After a 1-h period of stabilization, the first of three collection periods was initiated. The animals were each primed with $1 \mathrm{~mL}$ of saline containing inulin $(300 \mathrm{mg} / \mathrm{kg})$ and sodium PAH $(2 \mathrm{mg})$. They were then submitted to continuous infusion of saline solution containing inulin $(15 \mathrm{~g} / \mathrm{L})$ and $\mathrm{PAH}(4 \mathrm{mg} / \mathrm{L})$ at $0.08 \mathrm{~mL} / \mathrm{min}$. Concentrations of inulin and PAH were measured colorimetrically in plasma, as well as in urine, for estimation of GFR (25) and RPF (26). Blood and urine $\mathrm{Na}^{+}$were measured using an ion selective electrode (Ciba-Corning $614 \mathrm{Na} / \mathrm{K}$ analyzer Bayer/Ciba-Corning, USA). Net acid excretion (NAE) was calculated using the formula $\mathrm{NAE}=\mathrm{TA}+\mathrm{NH}_{4}-\mathrm{HCO}_{3}$, where TA is titratable acidity in urine (measured by microtitration of $0.01 \mathrm{M}$ sodium hydroxide), $\mathrm{NH}_{4}$ is the amount of ammonium excreted (evaluated by colorimetry) (27), and $\mathrm{HCO}_{3}$ is the net bicarbonate excretion (calculated using a model 248 Ciba-Corning $\mathrm{pH} / \mathrm{blood}$ gas analyzer Bayer/Ciba-Corning, USA). For determination of protein excretion, rats were placed in metabolic cages and 24-h urine samples were collected. Proteinuria was measured every $4 \mathrm{wk}$, starting at 2 mo and continuing throughout the study period. Protein concentration was measured by precipitation with $3 \%$ sulfosalicylic acid.

Light microscopy. The kidneys of 2018 -mo-old rats (6 from group CA18, 9 from group R18, and 5 from group RA18) were fixed in Bouin's solution and processed for paraffin embedding. Histologic sections (3 $\mu \mathrm{m}$ thick) were stained with Masson trichrome, and examined under light microscopy. The percentage of glomeruli exhibiting focal or global glomerulosclerosis, which was evidenced by segmental increases in the glomerular matrix, segmental collapse, obliteration of capillary lumina, and hyaline accumulation was determined. Tubulointerstitial injury was defined as inflammatory cell infiltrates and tubular dilatation, accompanied by atrophy or interstitial fibrosis. Injury was graded according to Shih et al. (28) on a scale of 0 to 4: none (score, 0 ); small focal areas (score, 0.5 ); involvement of $<10 \%$ (score, 1); involvement of $10-25 \%$ (score, 2); involvement of $25-75 \%$ (score, 3); extensive damage involving $>75 \%$ (score, 4 ).

Morphometric study. Morphologic evaluation was performed as follows: both kidneys of six rats from each group were rapidly dissected out, cleaned of connective tissue, and weighed. Renal tissue samples were embedded in paraffin and sectioned into $3-\mu \mathrm{m}$ parallel slices. The average glomerular diameter was measured using a calibrated eyepiece, each value being the result of the arithmetic mean of two measures taken along two perpendicular axes.

Immunohistochemical studies. Twenty-two animals (4 from group C18, 4 from group CA18, 9 from group R18, and 5 from group RA18) were studied. When the animals reached 18 mo of age, the kidneys were dissected out and immediately weighed. Tissue samples were embedded in paraffin, sectioned into 3- $\mu \mathrm{m}$ slices, deparaffinized, and subjected to immunohistochemical staining (29).

The sections were incubated overnight at $4^{\circ} \mathrm{C}$ with either $1 / 1000$ anti- $\alpha-$ smooth muscle actin MAb or 1/500 anti-rat fibronectin antibody. Alternatively, they were incubated for $1 \mathrm{~h}$ at room temperature with either a 1/100 antidesmin MAb or a 1/1500 anti-vimentin MAb. The reaction product was detected using avidin-biotin-peroxidase complex (Vector Laboratories, Burlingame, CA). The color reaction was developed with 3, 3-diamino-benzidine (Sigma Chemical, St. Louis, MO), and the material was counterstained with methyl green, dehydrated, and mounted. For all biopsies, negative controls consisted of substitution of the primary antibody with an equivalent concentration of normal murine or rabbit IgG

Immunoperoxidase staining for $\alpha$-smooth muscle actin, as well as fibronectin, desmin, and vimentin were performed in either the glomerular or the tubulointerstitial area. Subsequently, either the tubulointerstitial area grid field or the glomerular tuft area was graded semiquantitatively and the mean score per biopsy calculated, on a blinded basis. Each score mainly reflects changes in extent rather than intensity of staining, and depended on the percentage of the glomerular tuft area or grid field showing positive staining: from $0 \%$ to 5\% (score, 0 ); 5 to $25 \%$ (score, I); 25 to $50 \%$ (score, II); 50 to $75 \%$ (score, III); $>75 \%$ (score, IV) (30). It has been stated that data obtained using the semiquantitative scoring system are not only reproducible among different observers but are also are highly correlated with those generated by computerized morphometry $(30,31)$.

Antibodies. Primary antibodies included a) 1A4, a murine $\mathrm{MAb}$ to $\mathrm{NH}_{2-}$ terminal synthetic decapeptide of $\alpha$-smooth muscle actin (DAKO, Glostrup, Denmark); b) a purified IgG fraction of polyclonal rabbit anti-rat fibronectin (Chemicon International, Temecula, CA); c) D33, a murine monoclonal $\mathrm{IgG}_{1}$ antibody against human desmin (DAKO); and d) V9, a murine monoclonal $\mathrm{IgG}_{1}$ antibody against human vimentin (DAKO).

Statistical analysis. Statistical analysis was performed by unpaired $t$ test, Mann-Whitney $U$ test, or by ANOVA, followed by the Scheffé test, where appropriate. Values that were not normally distributed were subjected to the 
Kruskal-Wallis test, followed by Dunn's posttest, when necessary. Statistical significance was defined as $p<0.05$. The results are expressed as mean \pm SEM.

\section{RESULTS}

Renal function. Food ingestion and final body weights were comparable among the groups. Glycemia remained at normal levels in all groups studied. As shown in Figure 1, L-Arg administration did not change the mean blood pressure (BP) levels in control rats. By 8 wk of age, intrauterine-foodrestricted animals had developed significantly higher pressures than the respective controls. This hypertension was stable and persisted until the end of the observation period. In RA rats, BP remained depressed throughout the experimental period.

As shown in Figure 2, the onset of progressive proteinuria was observed in group R at 9 mo of age. By $18 \mathrm{mo}$, it had increased nearly 2 -fold compared with that of age-matched control rats. In control rats, L-Arg administration did not change the protein excretion profile. However, in restricted rats, proteinuria was absent. In fact, even in 18-mo-old rats, low protein excretion levels were observed (9.86 in RA versus $21.98 \mathrm{mg} / 24 \mathrm{~h}$ in $\mathrm{R}$ ), indicating that some protection against glomerular injury had been attained.

As shown in Table 1, mean values for GFR in 18-mo-old rats in group R (R18) and RA (RA18) were significantly decreased when compared with those of 18-mo-old rats in groups $\mathrm{C}$ (C18) and CA (CA18). Supplementation with L-Arg did not change GFR in either control or restricted rats, but caused a decrease in RPF, leading to higher filtration fractions $( \pm 30 \%)$ that in the respective nonsupplemented rats. These results suggest that in this reduced nephron number model, hemodynamic response to L-Arg administration remains similar to that seen in controls.

As shown in Table 2, all aged animals maintained normal acid-base equilibrium, confirming that aging, per se, does not induce changes in this aspect of homeostasis. As also shown in this table, fractional excretion of $\mathrm{Na}$ was adequate in all studied groups, indicating that even in aged intrauterine-food-restricted rats, with or without L-Arg supplementation, tubular ion handling was preserved. Table 3 shows that administration of $\mathrm{L}-\mathrm{Arg}$ did not interfere with the ability to excrete acid in either control or restricted animals. These results reinforce the concept that even

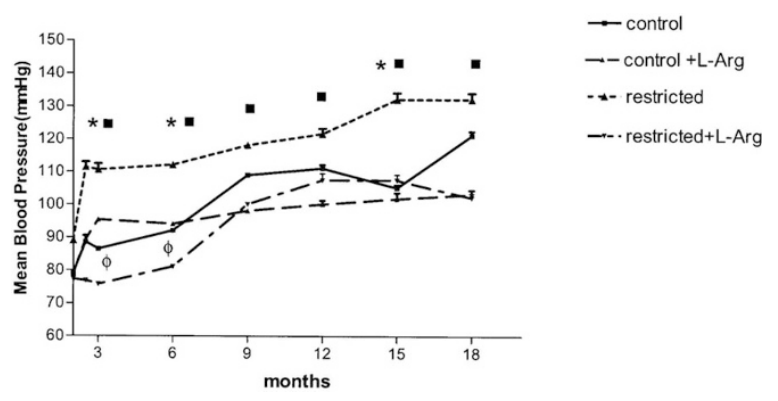

Figure 1. Effect of L-Arg on blood pressure (BP) in control (C) and intrauterine-food-restricted $(\mathrm{R})$ rats at different ages. Administration of $\mathrm{L}-\mathrm{Arg}$ did not change the $\mathrm{BP}$ of $\mathrm{C}$ rats but promoted a significant decrease in the $\mathrm{BP}$ of $\mathrm{R}$ rats. Comparisons were made among animals of the same age. Significance level: $p<0.05$ ( $*=\mathrm{C} v s \mathrm{R} ; \mathbf{\square}=\mathrm{R} v s \mathrm{RA} ; \emptyset=\mathrm{CA} v s \mathrm{RA})$; number of measurements, $n=12$ for all the groups.

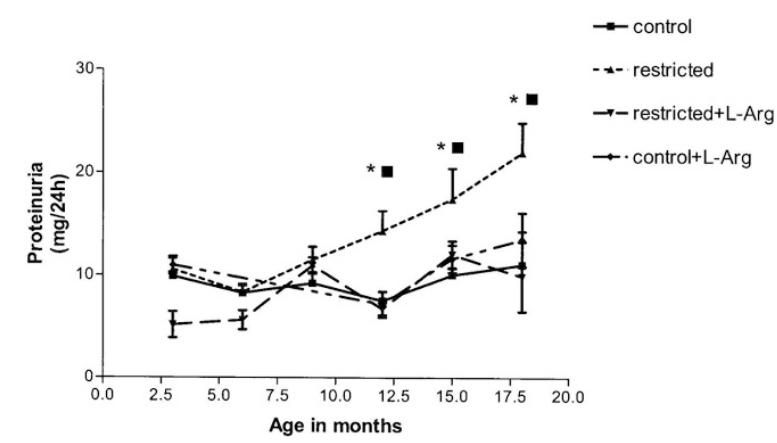

Figure 2. Effect of L-Arg on 24-h protein excretion of control and intrauterine-food-restricted rats. L-Arg administration promoted a significant decrease in proteinuria in aged intrauterine-food-restricted animals. Comparisons were made among animals of the same age. Significance level: $p<0.05$ ( $*=\mathrm{C}$ vs $\mathrm{R} ; \square=\mathrm{R} v s \mathrm{RA})$; number of measurements, $n=12$ for all groups.

older animals, in which nephron numbers are decreased, are able to maintain acid-base status. Moreover, our results suggest that, in this intake regime, L-Arg administration does not affect acid-base status or extracellular volume regulation.

Morphometric and histologic studies. The mean glomerular diameter was significantly greater in $\mathrm{R} 18$ rats than in $\mathrm{C} 18$ rats. On the other hand, in RA18 rats, mean glomerular diameter was comparable to that seen in C18 and CA18 rats (Fig. 3). These results suggest that L-Arg was able to suppress local or systemic factors that trigger hypertrophic stimuli.

Immunohistochemical and light microscopy studies. Treatment of the control rats with L-Arg did not affect any structural parameter investigated (data not shown).

Glomerular lesions were observed in the R18 group and not in the $\mathrm{C} 18$ group $(p<0.05)$. However, the higher percentage of glomeruli exhibiting focal or global glomerulosclerosis, as characterized by segmental increases in the glomerular matrix, segmental collapse and obliteration of capillary lumina, as well as by hyaline accumulation, was prevented by administration of L-Arg in group RA18 $(p<0.05)$. The tubulointerstitial compartment showed focal areas of tubular atrophy and/or dilatation with intraluminal casts, as well as interstitial mononuclear cell infiltration and fibrosis in the renal cortex of the intrauterine-food-restricted animals when compared with controls $(p<0.05)$. These alterations were not significant in the RA18 rats when compared with age-matched controls (Fig. 4).

The results of the immunohistochemical studies revealed that glomerular and cortical tubulointerstitial expression of fibronectin was higher in R18 rats $(p<0.05)$ (Figs. 5-7). In these animals, we also observed several foci of expanded interstitial and glomerular staining for fibronectin. Administration of and L-Arg reduced this alteration, although it did not prevent it. The RA18 animals presented greater fibronectin expression in the renal cortex and glomeruli than did the age-matched controls, CA18 $(p<0.01)$.

Immunohistochemical analysis also showed that R18 expressed higher levels of vimentin and $\alpha$-smooth muscle actin in the tubulointerstitial areas compared with control rats at the same age ( $p<0.05$; Figs. 5, 7, and 8). It has been previously described that, in normal rats, $\alpha$-smooth muscle actin was restricted to arterial smooth muscle cells. However, in the R18 
Table 1. Renal function parameters

\begin{tabular}{|c|c|c|c|c|}
\hline $\begin{array}{l}\text { Group } \\
(n)\end{array}$ & $\begin{array}{c}\text { GFR } \\
(\mathrm{m} / \mathrm{min} / \mathrm{kg})\end{array}$ & $\begin{array}{c}\mathrm{RPF} \\
(\mathrm{mL} / \mathrm{min} / \mathrm{kg})\end{array}$ & $\begin{array}{c}\mathrm{V} \\
(\mathrm{mL} / \mathrm{min} / \mathrm{kg})\end{array}$ & $\begin{array}{l}\mathrm{FF} \\
(\%)\end{array}$ \\
\hline C18 (39) & $4.19 \pm 0.10$ & $20.58 \pm 0.63$ & $0.079 \pm 0.003$ & $20.82 \pm 0.59$ \\
\hline CA18 (14) & $4.79 \pm 0.41$ & $14.97 \pm 0.88 *$ & $0.041 \pm 0.003 *$ & $32.49 \pm 2.96^{*}$ \\
\hline R18 (28) & $2.48 \pm 0.15^{*}$ & $17.38 \pm 0.75^{*}$ & $0.075 \pm 0.004$ & $14.05 \pm 0.72$ \\
\hline RA18 (25) & $2.44 \pm 0.10 \#$ & $13.43 \pm 0.38 \dagger$ & $0.033 \pm 0.001 \dagger$ & $18.29 \pm 0.75 \# \dagger$ \\
\hline
\end{tabular}

$* p<0.05$ vs $\mathrm{C} 18 ; \# p<0.05$ vs $\mathrm{CA} 18 ; \dagger p<0.05$ vs $\mathrm{R} 18$.

$\mathrm{V}$, urinary flow; FF, filtration fraction; C18, 18-mo-old control rats; CA18, 18-mo-old control rats with L-arginine supplementation; R-18, 18-mo-old intrauterine-food-restricted rats; RA18, 18-mo-old intrauterine-food-restricted rats with L-arginine supplementation.

Data expressed as mean \pm SEM; number $(n)$ of experiments given in parentheses.

Table 2. Acid-base data for control $(C)$ rats and intrauterine-food-restricted $(R)$ rats, receiving or not receiving L-arginine (A) supplementation

\begin{tabular}{|c|c|c|c|c|c|c|}
\hline $\begin{array}{l}\text { Group } \\
(n)\end{array}$ & Blood $\mathrm{pH}$ & $\mathrm{PCO}_{2}$ & $\begin{array}{c}\text { Blood } \mathrm{HCO}_{3} \\
(\mathrm{mEq} / \mathrm{L})\end{array}$ & Urinary $\mathrm{pH}$ & $\begin{array}{c}\text { Urinary } \mathrm{HCO}_{3} \\
(\mathrm{mEq} / \mathrm{L})\end{array}$ & $\begin{array}{r}\text { FENa } \\
(\%)\end{array}$ \\
\hline C18 (16) & $7.39 \pm 0.006$ & $40.1 \pm 1.1$ & $23.15 \pm 0.63$ & $6.29 \pm 0.30$ & $1.62 \pm 0.13$ & 0.57 \\
\hline CA18 (18) & $7.38 \pm 0.003$ & $36.7 \pm 2.5$ & $21.32 \pm 2.99$ & $6.64 \pm 0.06$ & $0.64 \pm 0.03 *$ & 0.51 \\
\hline RA18 (16) & $7.39 \pm 0.01$ & $32.5 \pm 1.3 \dagger$ & $19.6 \pm 0.56$ & $6.35 \pm 0.06$ & $1.93 \pm 0.32 \dagger$ & 0.24 \\
\hline
\end{tabular}

$* p<0.05$ vs $\mathrm{C} 18 ; \dagger p<0.05$ vs $\mathrm{R} 18$.

$\mathrm{PCO}_{2}$, arterial carbon dioxide tension; $\mathrm{HCO}_{3}$, bicarbonate; FENa, fractional excretion of sodium; C18, 18-mo-old control rats; CA18, 18-mo-old control rats with L-arginine supplementation; R-18, 18-mo-old intrauterine-food-restricted rats; RA18, 18-mo-old intrauterine-food-restricted rats with L-arginine supplementation.

Data expressed as mean \pm SEM; number $(n)$ of experiments given in parentheses.

Table 3. Urinary acid excretion in control $(C)$ rats and intrauterine-food-restricted $(R)$ rats, receiving or not receiving L-arginine $(A)$ supplementation

\begin{tabular}{lllll}
\hline Group & \multicolumn{1}{c}{$\begin{array}{c}\mathrm{TA} \\
(\mu \mathrm{Eq} / \mathrm{min} / \mathrm{kg})\end{array}$} & $\begin{array}{c}\mathrm{NH}_{4} \\
(\mu \mathrm{Eq} / \mathrm{min} / \mathrm{kg})\end{array}$ & $\begin{array}{c}\mathrm{HCO}_{3} \\
(\mu \mathrm{Eq} / \mathrm{min} / \mathrm{kg})\end{array}$ & $\begin{array}{c}\mathrm{NAE} \\
(\mu \mathrm{Eq} / \mathrm{min} / \mathrm{kg})\end{array}$ \\
\hline C18 & $0.78 \pm 0.06(38)$ & $1.54 \pm 0.06(38)$ & $0.121 \pm 0.01(36)$ & $2.12 \pm 0.096(36)$ \\
CA18 & $0.49 \pm 0.05(8)$ & $1.79 \pm 0.37(8)$ & $0.023 \pm 0.002 *(8)$ & $1.67 \pm 0.21(8)$ \\
R18 & $0.75 \pm 0.08(24)$ & $1.61 \pm 0.17(24)$ & $0.096 \pm 0.01(20)$ & $2.28 \pm 0.19(20)$ \\
RA18 & $1.04 \pm 0.15 \# \dagger(12)$ & $1.54 \pm 0.77(12)$ & $0.057 \pm 0.03(12)$ & $2.52 \pm 0.24(12)$ \\
\hline
\end{tabular}

$* p<0.05$ vs $\mathrm{C} 18 ; \# p<0.05$ vs $\mathrm{CA} 18 ; \dagger p<0.05$ vs $\mathrm{R} 18$.

TA, titratable acid; $\mathrm{NH}_{4}$, ammonium excretion; $\mathrm{HCO}_{3}$, excreted bicarbonate; NAE, net acid excretion; C18, 18-mo-old control rats; CA18, 18-mo-old control rats with L-arginine supplementation; R-18, 18-mo-old intrauterine-food-restricted rats; RA18, 18-mo-old intrauterine-food-restricted rats with L-arginine supplementation.

Data expressed as mean $\pm \mathrm{SEM}$; number $(n)$ of experiments given in parentheses.

group, we observed that there was also immunostaining for vimentin and $\alpha$-smooth actin in several tubular and interstitial areas, suggesting tubulointerstitial damage. Vimentin is an indicator of tubular cell regeneration, which is suggestive of recent injury (32). Administration of L-Arg prevented these increases (Fig. 5). In the diseased kidney, the de novo expression of $\alpha$-smooth muscle actin has been demonstrated to specifically label activated mesangial cells and interstitial myofibroblasts $(33,34)$. The results of our studies indicated the presence of glomerular and interstitial myofibroblasts in the kidneys of R18 rats. Administration of $\mathrm{L}$-Arg prevented this alteration.

The animals submitted to intrauterine food restriction also had higher expression of desmin at the glomerular edge compared with age-matched controls $(p<0.05)$ (Fig. 6). Typically, glomerular desmin expression is restricted to mesangial cells, being present in podocytes only following injury $(31,35,36)$. Several studies have shown that desmin expression at the glomerular edge was associated with podocyte damage $(31,35$,
36). Desmin expression at the glomerular edge was not modified by administration of L-Arg (Figs. 6 and 8).

\section{DISCUSSION}

It has long been recognized that nephron injury and hypertension are closely related. However, complex mechanisms control both the degree of renal involvement in the development of hypertension and the impact of hypertension on the development of renal injury. Some experimental models have indicated that reduced nephron number is a common denominator of hypertensive states, although unilateral nephrectomy may or may not be accompanied by hypertension $(37,38)$. In the present study, renal function in the aged rat was monitored in an experimental model (intrauterine food restriction) in which a known reduction in nephron number is observed. This was done in an attempt to characterize the physiopathology of accelerated glomerulosclerosis in the absence of systemic hy- 


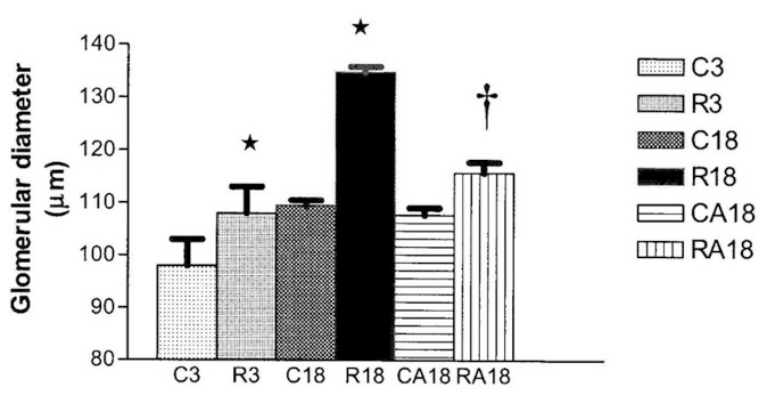

$\star p<0.05$ vs Control, at the same age $\div p<0.05$ vs R18

Figure 3. Mean glomerular diameter. Data from control rats and from intrauterine-food-restricted rats (R) supplemented or not with L-Arg (A). Both kidneys from six rats in each group were studied. Additional data from (16) were added to the figure. C3, 3-mo-old control rats; R3, 3-mo-old restricted rats. Significance level: $* p<0.05$ vs $\mathrm{C}$ of the same age; $\dagger p<0.05$ vs R18.
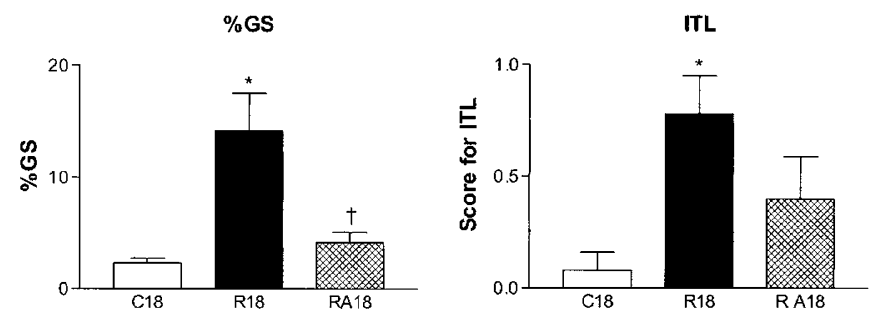

Figure 4. Percentage of glomeruli with glomerulosclerosis $(G S)$ and interstitial tubular lesions (ITL) in the renal cortex. Data from control rats $(\mathrm{C} 18, n=$ $5)$, from intrauterine-food-restricted rats $(\mathrm{R} 18, n=9)$ and from intrauterinefood restricted supplemented with L-Arg, $(\mathrm{RA} 18=5)$ group. Significance level: ${ }^{*} p<0.05$ vs $\mathrm{C} ; \dagger p<0.05$ vs $\mathrm{R}$.

pertension. In fact, L-Arg administration was able to prevent the hypertension observed in restricted rats throughout the experimental period. This finding complements our previous data (16), in which an early increase in blood pressure was observed in this same model and was corrected by L-Arg administration. Decreased excretion of $\mathrm{NO}_{2}+\mathrm{NO}_{3}$ in 3-mo-old intrauterine-food-restricted animals was also observed (16), suggesting endothelial dysfunction due to a decrease in $\mathrm{NO}$ synthesis. The role of NO in regulating blood pressure and glomerular hemodynamics was previously demonstrated by Zatz and Baylis (39). These authors showed that administration of NOS blockers to normal rats leads to changes in both systemic blood pressure levels and glomerular hemodynamics, stressing the role of this pathway in maintaining body homeostasis. Prolonged administration of NOS blockers was also shown to promote glomerular apoptosis in a SHR model (40). On the other hand, Vaziri et al. (41) demonstrated upregulation of renal and vascular endothelial NOS. The authors also found inducible NOS in 9-wk-old SHR rats, whereas, at 63 wk of age, SHR rats presented low urinary $\mathrm{NOx}\left(\mathrm{NO}_{2}+\mathrm{NO}_{3}\right)$ excretion and depressed renal and vascular NOS protein expression when compared with Wistar-Kyoto (WKY) rats of the same age. These authors suggested that, in young SHR, hypertension led to up-regulation of NOS, which could act as a

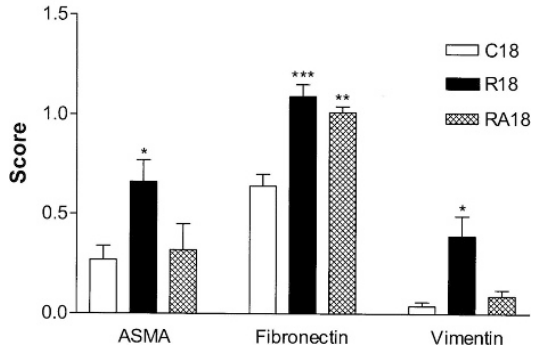

Figure 5. Score for $\alpha$-smooth muscle actin (ASMA), fibronectin, and vimentin in the renal cortex. Data from control rats $(\mathrm{C} 18, n=5)$, from intrauterinefood-restricted rats (R18, $n=9$ ), and from the intrauterine-food restricted supplemented with L-Arg group (RA18, $n=5$ ). Significance level: ${ }^{*} p<0.05$ vs $\mathrm{C} 18 ; * * p<0.01$ vs $\mathrm{C} 18$; *** $p<0.001$ vs $\mathrm{C} 18$.

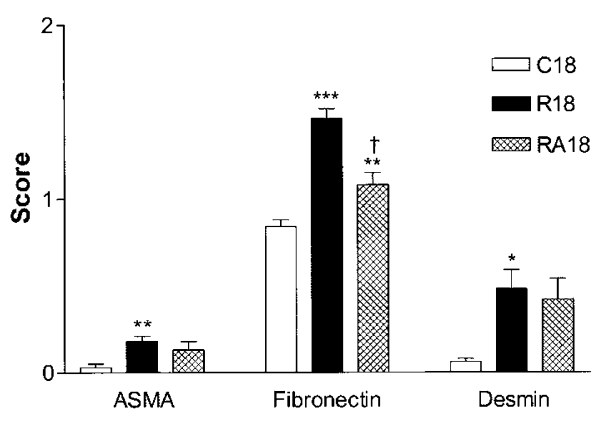

Figure 6. Score for $\alpha$-smooth muscle actin (ASMA), fibronectin, and desmin in glomeruli. Data from control rats $(\mathrm{C} 18, n=5)$, from intrauterine-foodrestricted rats (R18, $n=9)$ and from intrauterine-food restricted supplemented with L-Arg group (RA18, $n=5$ ). Significance level: * $p<0.05$ vs C18; ** $p<$ 0.01 vs $\mathrm{C} 18 ; * * * p<0.001$ vs $\mathrm{C} 18 ; \dagger p<0.01$ vs R18.

compensatory mechanism and attenuate the increase in blood pressure levels. In the aged SHR model, this up-regulation was not seen, suggesting that it could accelerate renal dysfunction. Our results concerning regulation of blood pressure in aged intrauterine-food-restricted rats submitted to long-term L-Arg administration confirms that disturbances in L-Arg-NO system are involved in the early and sustained hypertension observed in this experimental model. Low NO levels could, theoretically, be the result of L-Arg insufficiency, altered NO synthase activity or even decreased superoxide-dismutase (SOD) activity. Changes in SOD and increases in reactive oxygen species (ROS) have already been confirmed in this same model of intrauterine food restriction in 3-mo-old rats $(42,43)$. Reduced activity of NOS has also been described in aortas isolated from intrauterine-food-restricted rats (44). Although we did not measure urinary NOx and NOS protein expression in the present study, L-Arg supplementation corrected both hypertension and proteinuria, suggesting that this maneuver attenuates the vascular release of superoxide anions and restores NO production, as has been previously demonstrated in hypercholesterolemic rabbits (20). By stimulating NO production, L-Arg supplementation may also act as a vasodilator in arteriolar resistance, leading to a decrease in renal blood flow but maintaining GFR unchanged.

In this study, L-Arg supplementation began after weaning, in a time when nephrogenesis is complete and new nephron formation is therefore not expected (45). In several models of 


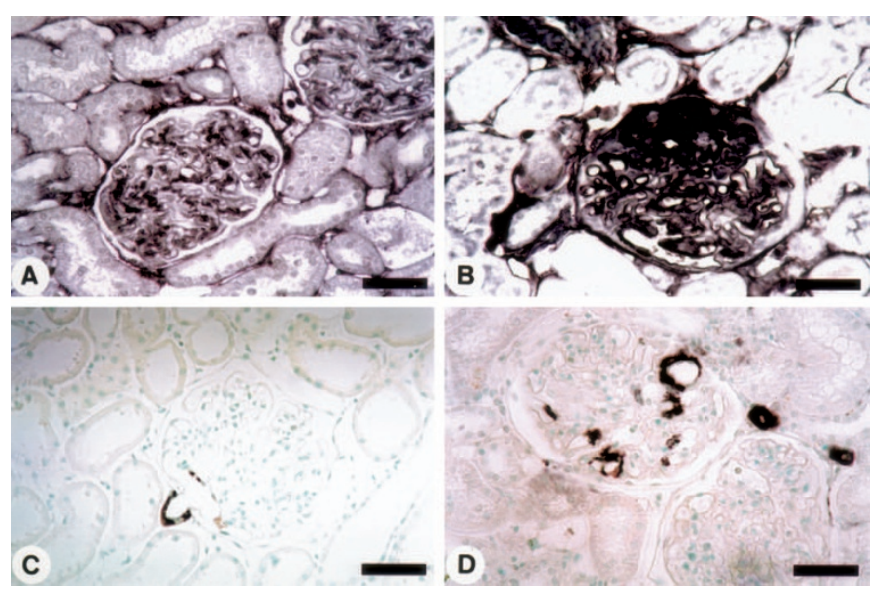

Figure 7. Immunolocalization of fibronectin $(A$ and $B)$ and $\alpha$-smooth muscle actin $(C$ and $D)$ in the renal cortex of a rat submitted to intrauterine food restriction and supplemented with L-Arg $(B$ and $D)$, together with data from an 18-mo-old control rat $(A$ and $C$ ). Note that the immunostaining for fibronectin in glomeruli and cortical tubulointerstitium is more intense in B than in A. Scale bars $=50 \mu \mathrm{M}$.

reduced nephron numbers, systemic hypertension and glomeruli hypertrophy have been interpreted as compensatory mechanisms with the purpose of maintaining adequate renal function. In a previous study (16), we observed early systemic hypertension in intrauterine-food-restricted rats at $8 \mathrm{wk}$ of age. This hypertension normalized after L-Arg administration. Our data show that, although L-Arg prevented hypertension, glomerular injury still occurred probably because all the restricted animals present a reduced nephron numbers. Besides this, the higher filtration fractions observed in these animals could be reflecting an increase in the glomerular capillary pressure. An imbalance of intraglomerular forces can results in podocyte stretch, damage, or loss with enhancement in desmin expression at the glomerular edge. It has been shown that desmin expression at the glomerular edge labels podocytes, which have been damaged $(31,34,35)$. There is also evidence that mesangial stretching stimulates extracellular matrix (ECM) production by these cells and commonly, fibronectin is the first ECM component that may deposit (46).

As shown in our previous study, L-Arg caused a significant increase in GFR in young animals. However, in 3-mo-old rats, the effect of sensitivity to L-Arg administration on renal function parameters was not apparent (16). In the present study, filtration fractions increased significantly, not only in RA18 rats but also in CA18 rats, suggesting that renal vascular response to L-Arg is restored. This finding reinforces our previous study (16), in which we showed that L-Arg restored acetylcholine-induced relaxation in mesenteric arteries of intrauterine-food-restricted rats. According to Tan et al. (47), NO is of fundamental importance in preserving renal functionality in the aging rat and we have demonstrated that this dependency is preserved even in aged intrauterine-food-restricted rats.

Our data show that proteinuria was avoided in RA18 rats, suggesting that $\mathrm{L}$-Arg exerted some protection with regard to glomerular permeability to macromolecules. In a previous study of 2- and 3-mo-old intrauterine-food-restricted rats, we
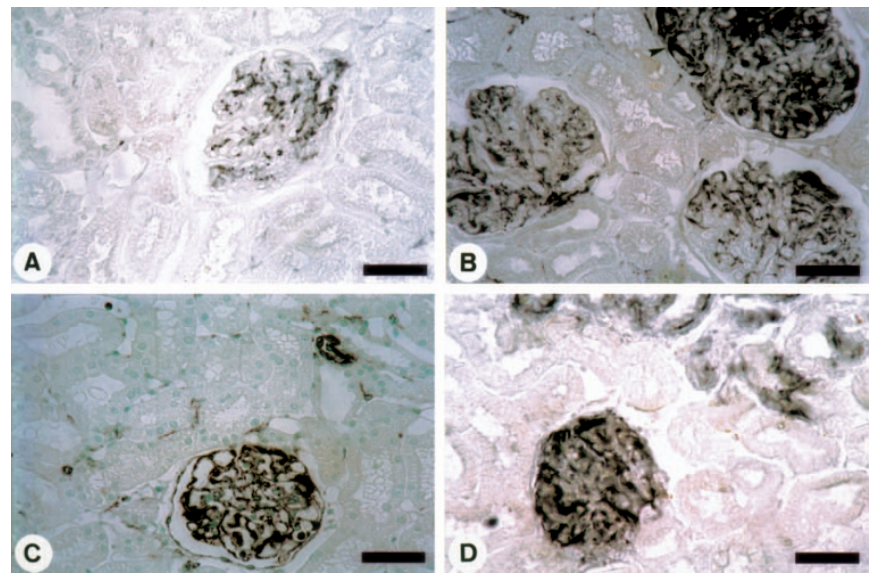

Figure 8. Immunolocalization of desmin $(A$ and $B)$ and vimentin $(C$ and $D)$ in the renal cortex of a rat submitted to intrauterine food restriction and supplemented with L-Arg $(B$ and $D)$ and of a control rat $(A$ and $C)$. Note that the immunostaining for vimentin at the glomeruli edge is more intense in $B$ than in $A$. Scale bars $=50 \mu \mathrm{M}$.

showed that, although 24-h protein excretion was within normal limits (below $10 \mathrm{mg}$ ), administration of L-Arg induced a profound reduction in protein excretion (16). This effect was also shown by Reckelhoff et al. (19) in 12- to 13-mo-old rats whose diets were supplemented with L-Arg for long periods of time. On the other hand, albuminuria was observed in a chronic model of NO inhibition, due to functional rather than structural disruption of the glomerular wall (48). Taken together, these data indicate that the L-Arg-NO system can play an important role in regulating renal handling of proteins.

It is known that hypertension alone plays an important role in the progression of renal disease. A persistent elevation in blood pressure can be transmitted to glomeruli and lead to progressive injury, which can, in turn, aggravate systemic hypertension. For example, in aging SHR rats, Tolbert et al. (49) demonstrated that, at 9 mo of age, glomerular hypertension develops due to a slight increase in systemic blood pressure and a decline in preglomerular vascular resistance, allowing transmission of elevated systemic pressure to glomerular capillaries. These hemodynamic changes were not a response to injury, since vascular and glomerular morphologies were normal at this age. The authors postulated that the late onset of glomerular hypertension could contribute to the subsequent appearance of glomerular sclerosis and progressive renal failure in these rats. In a model of renal ablation performed in newborn rats, Woods et al. (50) showed that hypertension develops after $8 \mathrm{wk}$ of age and proteinuria is significantly higher at $20 \mathrm{wk}$, suggesting that hypertension precedes glomerular damage, which is significant only in the older group. Our data show that in RA18, glomeruli show no changes in diameter, or, in other words, that hypertrophy was prevented by L-Arg administration. Therefore, two important factors that contribute to the progression of renal disease, systemic hypertension and glomerular hypertrophy, were absent in RA18 rats. However, glomerular involvement was still present, as evidenced by the increased desmin expression seen at the edges of podocytes in RA18 rats, suggesting that changes 
during renal development are fundamental in determining the quality of kidney function later in life. Our data are similar to the findings reported by Floege et al. (35) in Milan normotensive rats, in which early podocyte damage was observed preceding glomerulosclerosis in the absence of systemic hypertension, hyperglycemia, and glomerular hypertension. The authors demonstrated significant up-regulation of desmin expression in the glomeruli of young Milan rats, and this upregulation preceded all other glomerular alterations.

In conclusion, our results suggest that, although hypertension occurs early in the intrauterine-food-restriction model, it is only partially responsible for kidney involvement since normalization of blood pressure levels did not completely prevent glomerular alterations. Our data reinforce the concept that, although the L-Arg-NO system exerts significant influence over vascular sensitivity in the offspring of intrauterine-foodrestricted mothers, decreased nephron number remains one of the main trigger factors for renal involvement in adulthood. On the other hand, our data confirm the Barker hypothesis that cardiovascular and related disorders originate from fetal adaptations to maternal undernutrition, which permanently alters growth rates, as well as postnatal physiology and metabolism.

Acknowledgments. The authors thank Letícia Megumi Odo for her technical assistance.

\section{REFERENCES}

1. Barker DJ, Osmond C, Golding J, Kuh D, Wadsworth ME 1989 Growth in utero, blood pressure in childhood and adult life and mortality from cardiovascular disease. BMJ 298:564-567

2. Barker DJ 1995 Fetal origins of coronary heart disease. BMJ 311:171-174

3. Campbell DM, Hall MH, Barker DJ, Cross J, Shiell AW, Godfrey KM 1996 Diet in pregnancy and the offspring's blood pressure 40 years later. Br J Obstet Gynaecol 103:273-280

4. Barker DJ 1988 In utero programming of chronic disease. Clin Sci (Lond) 95:115128

5. Lucas SR, Zaladek-Gil F, Costa-Silva VL, Miraglia SM 1991 Function and morphometric evaluation of intrauterine undernutrition on kidney development of the progeny. Braz J Med Biol Res 24:967-970

6. Lucas SRR, Costa Silva VL, Miraglia SM, Zaladek Gil F 1997 Functional and morphometric evaluation of offspring kidney after intrauterine undernutrition. Pediatr Nephrol 11:719-723

7. Merlet-Benichou C, Gilbert T, Muffat-Joly M, Lelievre-Pegorier M, Leroy B 1994 Intrauterine growth retardation leads to a permanent nephron deficit in the rat. Pediatr Nephrol 8:175-180

8. Welham SJ, Wade A, Woolf AS 2002 Protein restriction in pregnancy is associated with increased apoptosis of mesenchymal cells at the start of rat metanephrogenesis. Kidney Int 61:1231-1242

9. Langley-Evans SC, Gardner DS, Welham SJ 1998 Intrauterine programming of cardiovascular disease by maternal nutritional status. Nutrition 14:39-47

10. Woods LL, Ingelfinger JR, Nyengaard JR, Rasch R 2001 Maternal protein restriction suppresses the newborn renin-angiotensin system and programs adult hypertension in rats. Pediatr Res 49:460-467

11. Manning J, Beutler K, Knepper MA, Vehaskari VM 2002 Upregulation of renal BSC1 and TSC in prenatally programmed hypertension. Am J Physiol Renal Physiol 283:F202-F206

12. Anderson S, Brenner BM 1986 Effects of aging on the renal glomerulus. Am J Med $80: 435-442$

13. Melk A, Halloran PF 2001 Cell senescence and its implications for nephrology. J Am Soc Nephrol 12:385-393

14. Couser WG, Stilmant MM 1975 Mesangial lesions and focal glomerular sclerosis in the aging rat. Lab Invest 33:491-501

15. Lucas SRR, Miraglia SM, Zaladek Gil F, Coimbra TM 2001 Intrauterine food restriction as a determinant of nephrosclerosis. Am J Kidney Dis 37:467-476

16. Alves GM, Barão MA, Odo LN, Nascimento Gomes G, Franco Mdo C, Nigro D, Lucas SR, Laurindo FR, Brandizzi LI, Zaladek Gil F 2002 L-Arginine effects on blood pressure and renal function of intrauterine restricted rats. Pediatr Nephrol 17:856-62

17. Reyes AA, Purkerson ML, Karl I, Klahr S 1992 Dietary supplementation with L-arginine ameliorates the progression of renal disease in rats with subtotal nephrectomy. Am J Kidney Dis 20:168-176
18. Reyes AA, Karl IE, Kissane J, Klahr S 1993 L-arginine administration prevents glomerular hyperfiltration and decreases proteinuria in diabetic rats. J Am Soc Nephrol 41:1039-1045

19. Reckelhoff JF, Kellum JÁ Jr, Racusen LC, Hildebrandt DA 1997 Long-term dietary supplementation with L-arginine prevents age-related reduction in renal function. Am J Physiol 272:R1768-R1774

20. Boger RH, Bode-Boger SM, Mugge A, Kienke S, Brandes R, Dwenger A, Frolich JC 1995 Supplementation of hypercholesterolaemic rabbits with L-arginine reduces the vascular release of superoxide anions and restores NO production. Atherosclerosis 117:273-284

21. Brenner BM, Garcia DL, Anderson S 1988 Glomeruli and blood pressure. Less of one, more the other? Am J Hypertens 1:335-347

22. Klag MJ, Whelton PK, Randall BL, Neaton JD, Brancati FL, Ford CE, Shulman NB, Stamler J 1996 Blood pressure and end-stage renal disease in men. N Engl J Med 334:13-18

23. Marcantoni C, Jafar TH, Oldrizzi L, Levey AS, Maschio G 2000 The role of systemic hypertension in the progression of nondiabetic renal disease. Kidney Int Suppl 75:S44-S48

24. de Carmo Pinho Franco M, Nigro D, Fortes ZB, Tostes RC, Carvalho MH, Lucas SR, Gomes GN, Coimbra TM, Gil FZ 2003 Intrauterine undernutrition-renal and vascular origin of hypertension. Cardiovasc Res 60:228-234

25. Flores-Mendonza I, Mello Aires M, Malnic G 1979 Effect of furosemide on urinary acidification during alterations of acid-base equilibrium in the rat. J Bras Nefrol $1: 51-58$

26. Smith HW, Finkelstein N, Aliminosa L, Grawford B, Graber M 1945 The renal clearances of substituted hippuric acid derivatives and other aromatic acids in dog and man. J Clin Invest 24:388

27. Connerty VH, Angles MD, Briggs R, Eaton EH 1957 Determination of urinary ammonia (nitrogen) by means of direct nesslerization. Am J Clin Pathol 28:634-638

28. Shih W, Hines WH, Nielson EG 1988 Effects of cyclosporin A on the development of immune-mediated interstitial nephritis. Kidney Int 33:1113-1118

29. Johnson RJ, Garcia RL, Pritzl P, Alpers CE 1990 Platelets mediate glomerular cell proliferation in immune complex nephritis induced by anti-mesangial cell antibodies in the rat. Am J Pathol 136:369-374

30. Kliem V, Johnson RJ, Alpers CE, Yoshimura A, Couser WG, Koch KM, Floege J 1996 Mechanisms involved in the pathogenesis of tubulointerstitial fibrosis in 5/6nephrectomized rats. Kidney Int 49:666-678

31. Coimbra TM, Janssen U, Gröne HJ, Ostendorf T, Kunter U, Schmidt H, Brabant G, Floege J 2000 Early events leading to renal injury in obese Zucker (fatty) rats with type II diabetes. Kidney Int 57:167-182

32. Gröne HJ, Weber K, Gröne E, Helmchen U, Osborn M 1987 Coexpression of keratin and vimentin in damaged and regenerating tubular epithelia of the Kidney. Am J Pathol 129:1-8

33. Johnson RJ, Iida H, Alpers CE, Majesky MW, Schwartz SM, Pritzl P, Gordon K, Gown AM 1991 Expression of smooth muscle cell phenotype by rat mesangial cells in immune complex nephritis. Alpha-smooth muscle actin is a marker of mesangial cell proliferation. J Clin Invest 87:847-858

34. Alpers CE, Hudkins KL, Floege J, Johnson RJ 1994 Human renal cortical interstitial cells with some features of smooth muscle cells participate in tubulointerstitial and crescentic glomerular injury. J Am Soc Nephrol 5:201-209

35. Floege J, Hackmann B, Kliem V, Kriz W, Alpers CE, Johnson RJ, Kuhn KW, Koch KM, Brunkhorst R 1997 Age-related glomerulosclerosis and interstitial fibrosis in Milan normotensive rats: a podocyte disease. Kidney Int 51:230-243

36. Floege J, Alpers CE, Sage EH, Pritzl P, Gordon K, Johnson RJ, Couser WG 1992 Markers of complement-dependent and complement-independent glomerular visceral epithelial cell injury in vivo. Expression of antiadhesive proteins and cytoskeletal changes. Lab Invest 67:486-497

37. Griffin KA, Picken MM, Churchill M, Churchill P, Bidani AK 2000 Functional and structural correlates of glomerulosclerosis after renal mass reduction in the rat. J Am Soc Nephrol 11:497-506

38. Moritz KM, Wintour EM, Dodic M 2002 Fetal uninephrectomy leads to prenatal hypertension and compromised renal function. Hypertension 39:1071-1076

39. Zatz R, Baylis C 1998 Chronic nitric oxide inhibition model six years on. Hypertension 32:958-964

40. Ono H, Ono Y, Takanohashi A, Matsuoka H, Frohlich ED 2001 Apoptosis and glomerular injury after prolonged nitric oxide synthase inhibition in spontaneously hypertensive rats. Hypertension 38:1300-1306

41. Vaziri ND, Wang XQ, Ni ZN, Kivlighn S, Shahinfar S 2002 Effects of aging and AT-1 receptor blockade on NO synthase expression and renal function in SHR. Biochim Biophys Acta 1592:153-161

42. Franco Mdo C, Akamine EH, DiMarco GS, Casarini DE, Fortes ZB, Carvalho MH 2003 NADPH oxidase and enhanced superoxide generation in the intrauterine undernourished rats: involvement of the renin-angiotensin system. Cardiovasc Res 59:767775

43. Franco Mdo C, Dantas AP, Akamine HE, Kawamoto EM, Fortes ZB, Scavone C, Tostes RC, Carvalho MH, Nigro D 2002 Enhanced oxidative stress as a potential mechanism underlying the programming of hypertension in utero. J Cardivasc Pharmacol 40:501-509

44. Franco Mdo C, Arruda RM, Dantas AP, Kawamoto EM, Fortes ZB, Scavone C, Carvalho MH, Tostes RC, Nigro D 2002 Intrauterine undernutrition: expression and activity of the endothelial nitric oxide synthase in male and female adult offspring. Cardiovasc Res 56:145-153 
45. Moritz KM, Wintour EM 1999 Functional development of the meso- and metanephros. Pediatr Nephrol 13:171-178

46. Riser BL, Cortes P, Zhao X, Bernstein J, Dumler F, Narins RG 1992 Intraglomerular pressure and mesangial stretching stimulate extracellular matrix formation in the rat. J Clin Invest 90:1932-1943

47. Tan D, Cernadas MR, Aragoncillo P, Castilla MA, Alvarez Arroyo MV, López Farre AJ, Casado S, Caramelo C 1998 Role of nitric oxide-related mechanism in renal function in ageing rats. Nephrol Dial Transplant 13:594-601
48. Arcos MI, Fujihara CK, Sesso A, Almeida Prado EB, de Almeida Prado MJ, de Nucci G, Zatz R 2000 Mechanisms of albuminuria in the chronic nitric oxide inhibition model. Am J Physiol Renal Physiol 279:F1060-F1066

49. Tolbert EM, Weisstuch J, Feiner HD, Dworkin LD 2000 Onset of glomerular hypertension with aging precedes injury in the spontaneously hypertensive rat. Am J Physiol Renal Physiol 278:F839-F846

50. Woods LL, Weeks DA, Rasch R 2001 Hypertension after neonatal uninephrectomy in rats precedes glomerular damage. Hypertension 38:337-342 